Diagnóstico por imágenes

Síndrome de banda amniótica

\title{
Amniotic band syndrome
}

Delgado Montano, Francisco Javier; Mena Ugarte, Sandra Carolina

\author{
Francisco Javier Delgado Montano \\ fjdm2010@gmail.com \\ Hospital Nacional de la Mujer "Dra. María Isabel \\ Rodríguez", El Salvador \\ Sandra Carolina Mena Ugarte \\ Hospital Nacional de la Mujer "Dra. María Isabel \\ Rodríguez", El Salvador
}

\author{
Alerta \\ Ministerio de Salud, El Salvador \\ ISSN-e: 2617-5274 \\ Periodicidad: Semestral \\ vol. 2, núm. 2, 2019 \\ ralerta@salud.gob.sv
}

Recepción: 13 Marzo 2019

Aprobación: 31 Marzo 2019

Publicación: 31 Julio 2019

URL: http://portal.amelica.org/ameli/journal/419/4191898014/

DOI: https://doi.org/10.5377/alerta.v2i2.7921

Autor de correspondencia: fjdm2010@gmail.com

Forma recomendada de citar: Delgado Montano FJ, Mena Ugarte

SC. Síndrome de banda amniótica. Alerta. 2019;2(2):188-193.

DOI: $10.5377 /$ alerta.v2i2.7921

\section{SÍNDROME DE BANDA AMNIÓTICA, UN DIAGNÓSTICO POR IMÁGENES}

El síndrome de banda amniótica es una condición rara ${ }^{1}$ que tiene una prevalencia de 1 en 1200. Es un espectro que incluye afectación de las extremidades, la región cráneo facial y del tronco, que puede encontrarse aislado o en combinación. Se debe aclarar que la presencia de las bandas no es necesario para el diagnóstico, es decir, pueden estar ausentes. Otro nombre que recibe esta patología es Complejo de Deformidad Amniótica, Adherencias y Mutilaciones (ADAM complex ${ }^{1}$, por sus siglas en inglés). Esta afectación ocurre generalmente entre el día 28 a la semana 18 de gestación, aunque puede haber afectaciones después de esta edad gestacional.

Algunas teorías sugieren causas intrínsecas, extrínsecas o iatrogénicas ${ }^{2}$. Cuando se realiza el diagnóstico de forma oportuna se pueden brindar pautas de tratamiento que posibiliten la liberación de las bandas

\section{NotAS DE AUTOR}


(cirugía fetal) $^{3}$. El pronóstico y el tratamiento dependen de la severidad de la deformación y generalmente requieren tratamientos reconstructivos extensos. Si la lesión se asocia a otras patologías como la secuencia Potter, la condición se hace incompatible con la vida ${ }^{4}$, aunque no hay una asociación directa con esta última enfermedad. No existe un aumento del riesgo de recurrencia, ni en la incidencia de anormalidades cromosómicas o síndromes genéticos asociados a las bandas amnióticas.

Esta patología puede involucrar anormalidades cráneofaciales como hendidura facial, hendidura palatina, microftalmia, así como también disrupciones de la formación del cráneo, ocasionando otros defectos como anencefalia y encefalocele, entre otras. Finalmente, el síndrome de banda amniótica puede tener múltiples presentaciones y el tratamiento para cada paciente debe individualizarse, para brindar el mejor abordaje como se sugiere actualmente 5 .

Las siguientes imágenes pertenecen a un caso de una mujer de 25 años de edad; a las 25 semanas de gestación, al feto se le diagnostica microcefalia más encefalocele, por lo cual es referida a tercer nivel para su atención y confirmación de la patología. En la ultrasonografía prenatal realizada en el hospital se describe pérdida de anatomía de la cabeza, dificultad para identificar la ecogenicidad del cráneo, pérdida de la continuidad a nivel parietofrontal izquierdo y también a nivel occipital (Figura 1 y Figura 2). En la evaluación por ultrasonido se hizo difícil establecer si se trataba de dos encefaloceles versus un acráneo exencéfalo.

La paciente dio a luz vía vaginal a un paciente de sexo masculino de 35 semanas de gestación (Ballard), de 1890 gramos de peso y 45 centímetros de talla. Al examen físico del recién nacido se encontró una pérdida total de la morfología facial, sindactilia del $4^{\circ}$ y $5^{\circ}$ dedo de la mano izquierda y dos masas en la región craneal.

Se realizó una resonancia magnética que concluye: hallazgos de encefalocele occipital y parietal derecho, así como ausencia de estructuras de la línea media por falta de configuración de los hemisferios cerebrales, ganglios basales y sistema ventricular (Figura 3, Figura 4, Figura 5 y Figura 6). Se realizó, como parte de los exámenes diagnósticos complementarios, una ultrasonografía transfontanelar que describe hallazgos de tejido cerebral en ambas masas craneales, lo que refuerza el diagnóstico de encefalocele. El paciente fue dado de alta para continuar sus controles en el Hospital Nacional de Niños Benjamín Bloom.

Desde el año 2016, en el Hospital Nacional de la Mujer se conforma el Comité de Medicina Fetal con el afán de brindar una atención multidisciplinaria a las mujeres de riesgo. Lo que se pretende con el comité es tratar de hacer un diagnóstico temprano y un abordaje oportuno de un feto con ciertas patologías (bidrops fetalis, cardiopatías congénitas, gastrosquisis, etc.,), con la intención de brindar las mejores condiciones al nacimiento. La intervención del comité incluye realizar un análisis y discusión de cada caso y coordinar con todas las instancias correspondientes la atención conjunta del feto con determinada patología. Pensando en mejorar la calidad de atención, ante cualquier ultrasonografía que sugiera una patología fetal, como el del caso arriba expuesto, es de vital importancia confirmar la sospecha clínica. La referencia oportuna a la institución puede mejorar el pronóstico de algunos casos, que si se abordan de manera tardía no la tendrían (ciertas cardiopatías, gastrosquisis, por mencionar algunos ejemplos). 


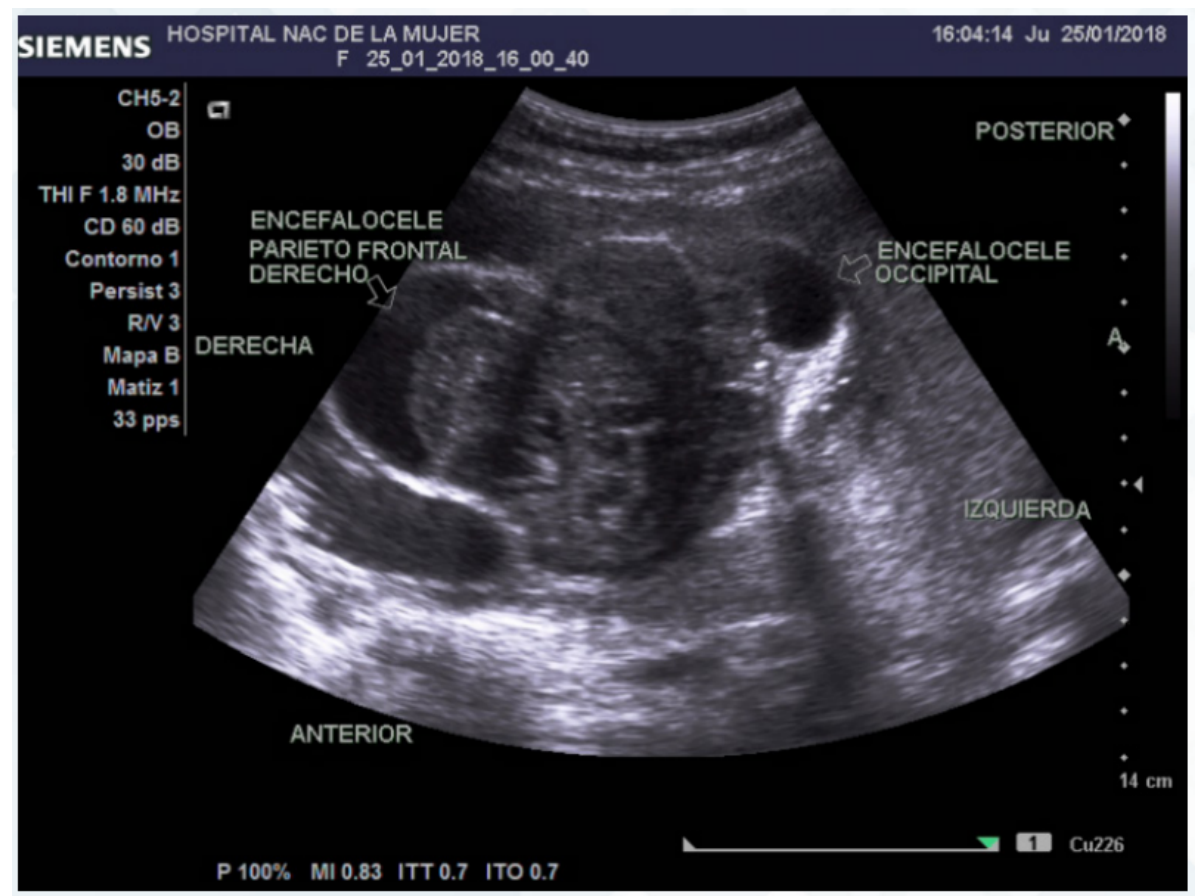

FIGURA 1

Ultrasonografía abdominal donde se muestran ambos encefaloceles Archivos digitales del Comité de Medicina Fetal del Hospital Nacional de la Mujer

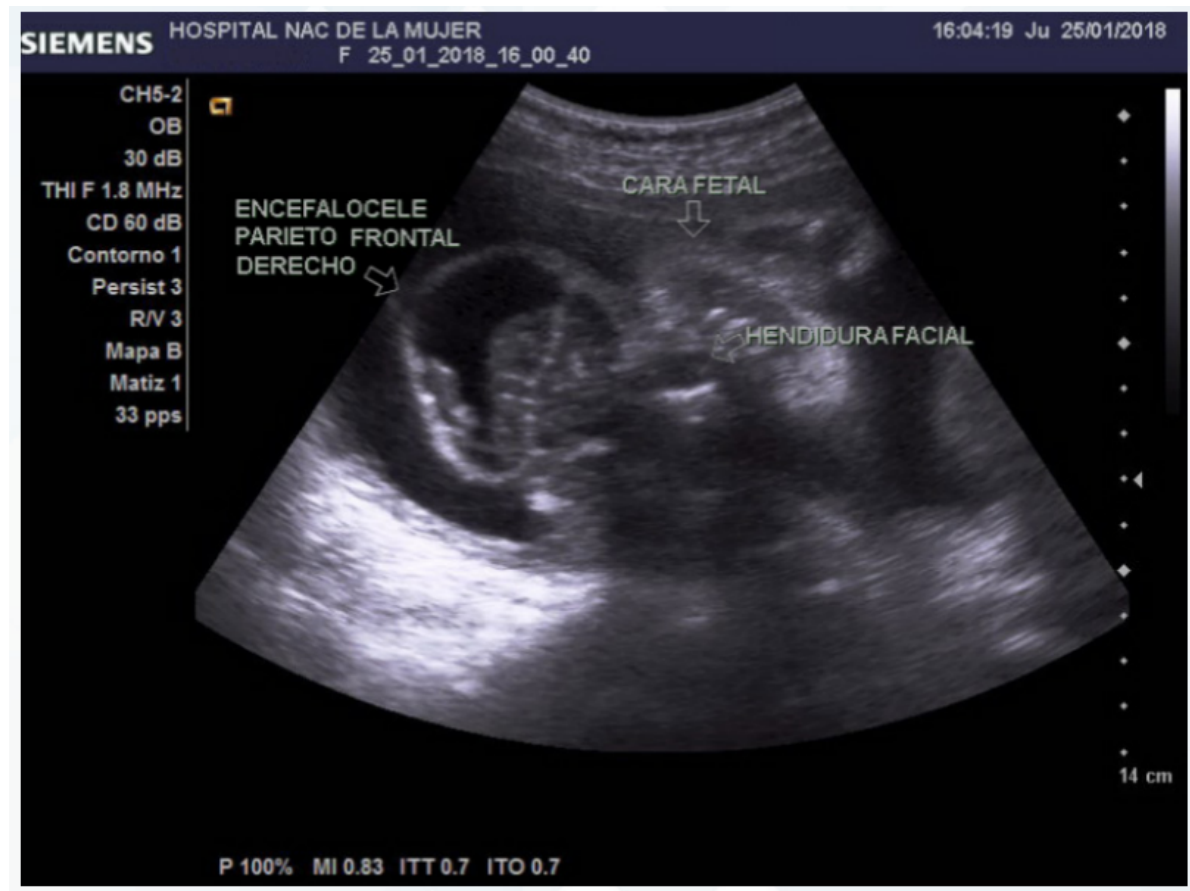

FIGURA 2

Ultrasonografía abdominal donde se observa la hendidura facial y su relación con el enfalocele derecho Archivos digitales del Comité de Medicina Fetal del Hospital Nacional de la Mujer 


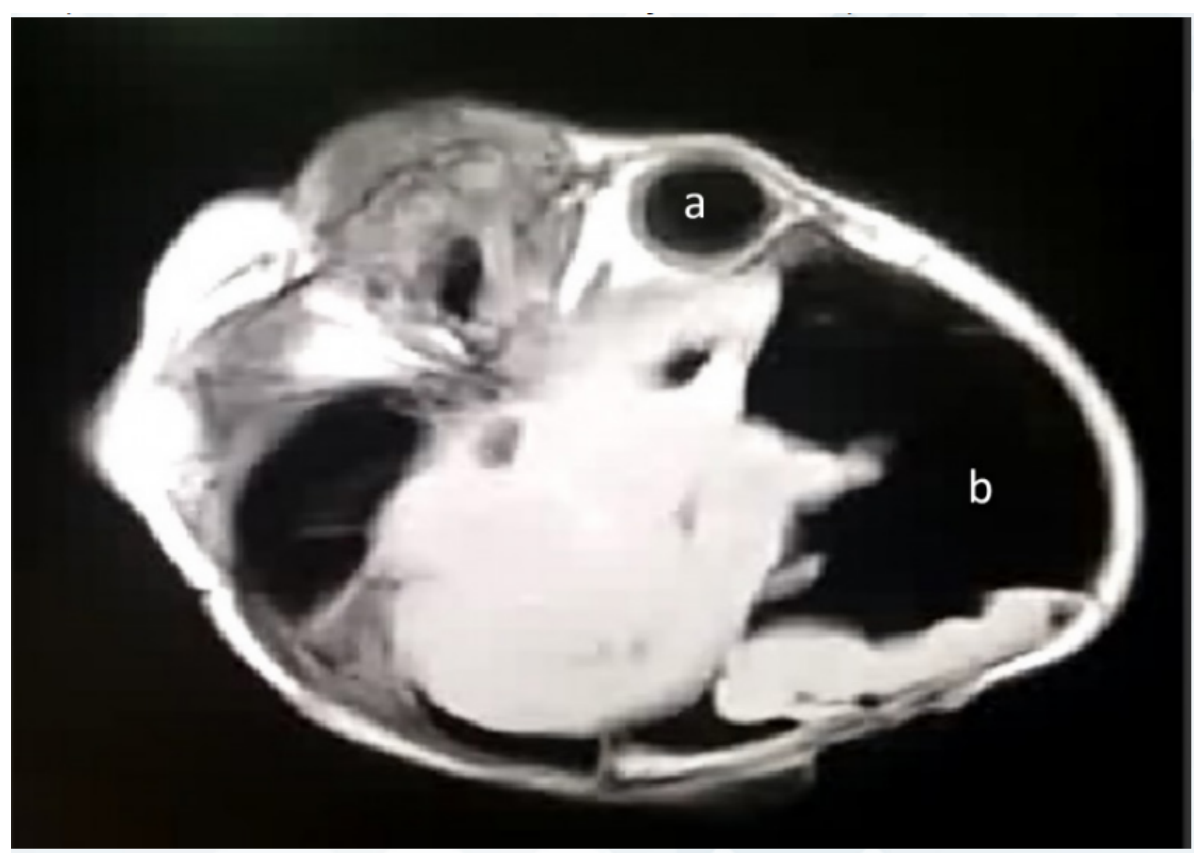

FIGURA 3

Corte transversal del cráneo que muestra una pérdida total de la anatomía del rostro del paciente. a. Globo ocular derecho. b. Tejido cerebral parte del encefalocele Archivos digitales del Comité de Medicina Fetal del Hospital Nacional de la Mujer

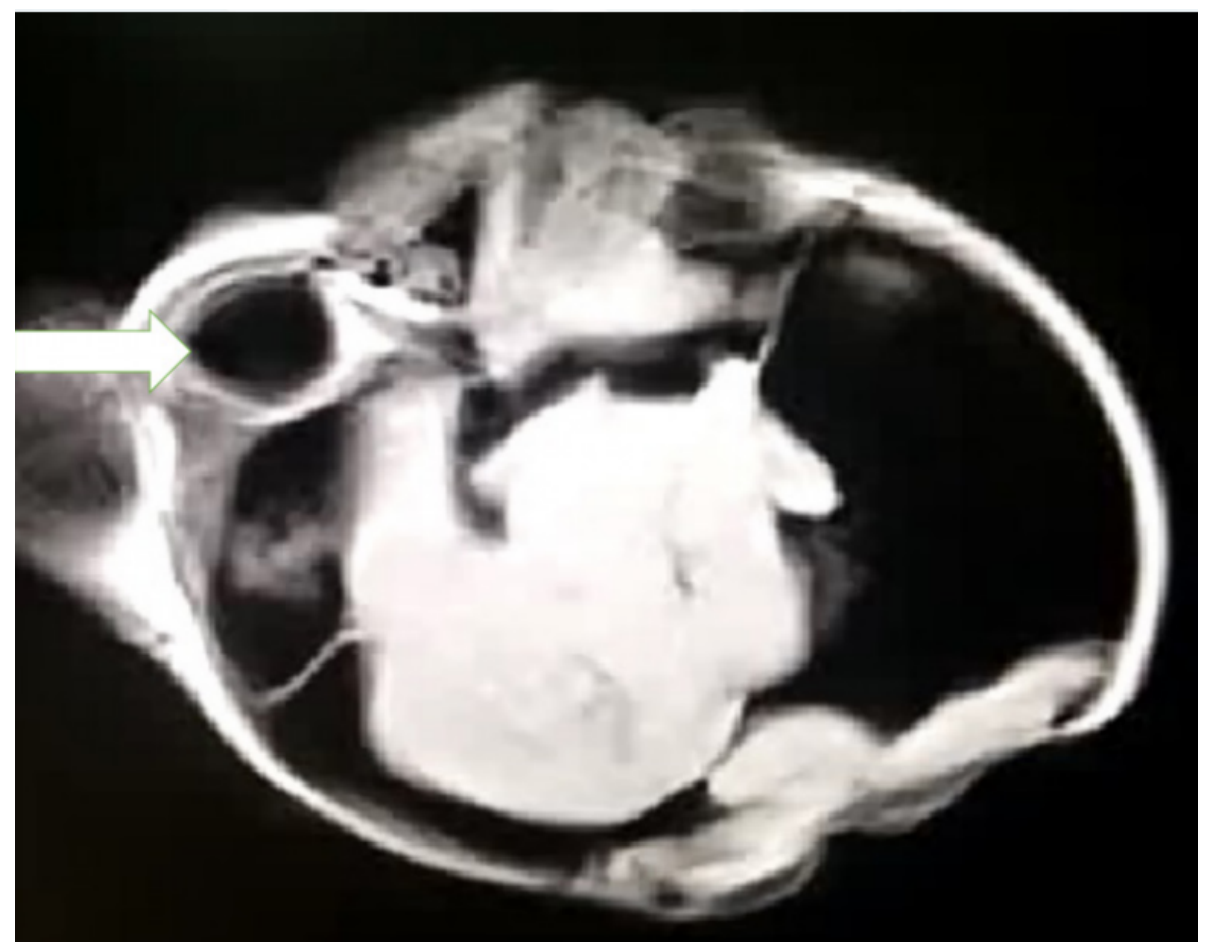

FIGURA 4

Corte coronal del cráneo, un corte más alto al anterior, donde se observa el globo ocular izquierdo señalado con una echa Archivos digitales del Comité de Medicina Fetal del Hospital Nacional de la Mujer 


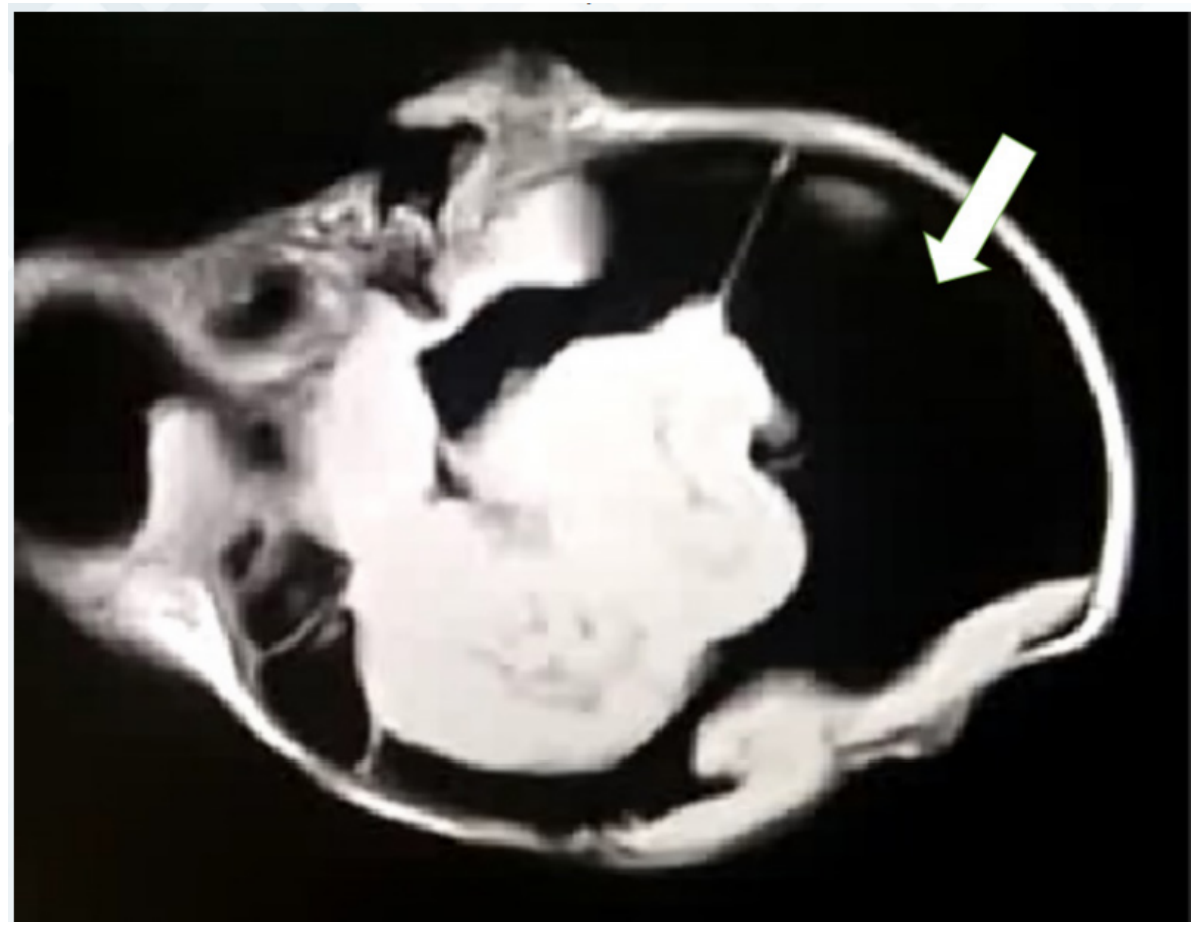

FIGURA 5

Corte transversal del cráneo y el encéfalo. A la derecha, señalado con flecha, parte del encefalocele parietal derecho Archivos digitales del Comité de Medicina Fetal del Hospital Nacional de la Mujer

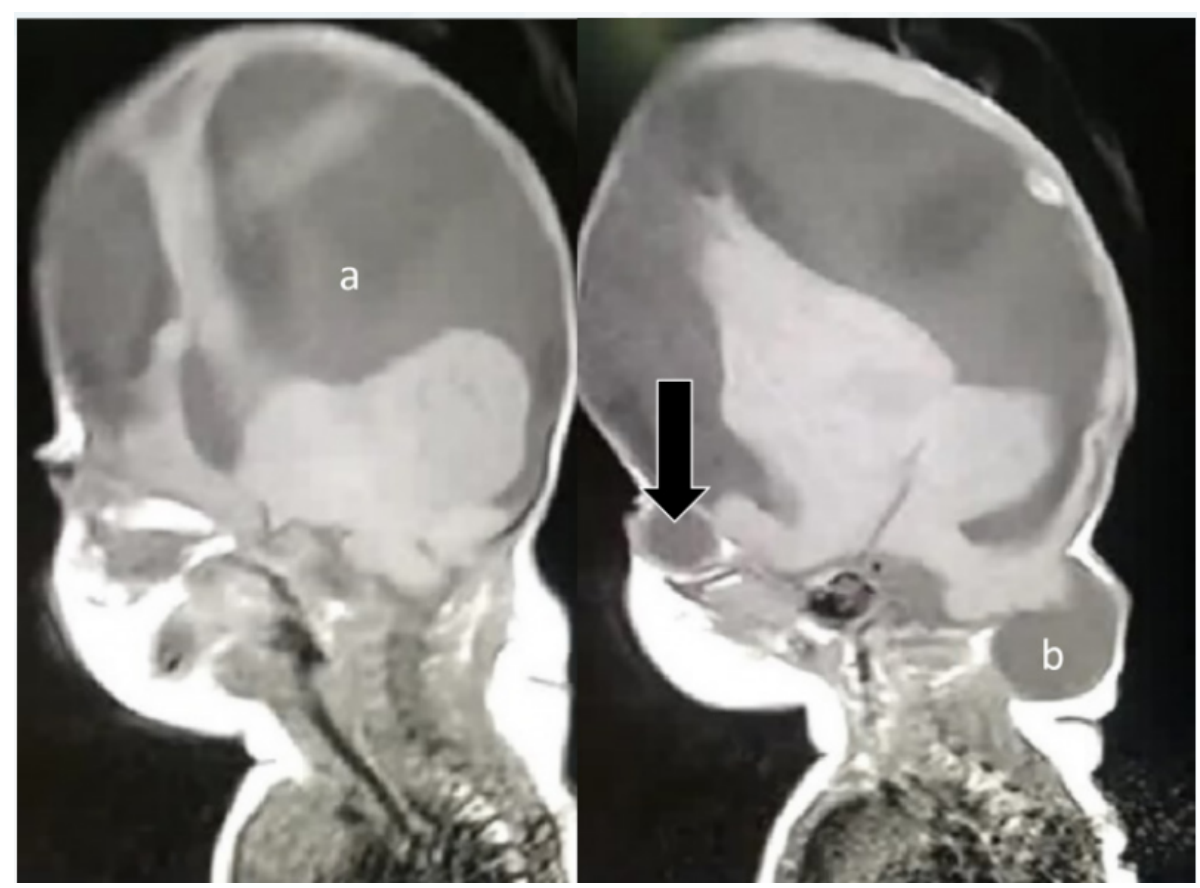

FIGURA 6

Cortes sagitales de la cabeza. Se observan dos encefaloceles: el parietofrontal derecho (a) y el occipital (b). La flecha señala el globo ocular Archivos digitales del Comité de Medicina Fetal del Hospital Nacional de la Mujer 


\section{REFERENCIAS BIBLIOGRÁficAS}

1. Shetty P, Menezes LT, Tauro LF, Diddigi KA. Amniotic Band Syndrome. The Indian Journal of Surgery. 2013;75(5):401-402. DOI: $10.1007 / s 12262-012-0468-x$

2. Díaz Primera RJ, Gil Guevara ED, Sánchez Jiménez R, Bermúdez González C. Cirugía fetal en bandas amnióticas. Revista Peruana de Ginecología y Obstetricia. 2018; 64(4):639-646. DOI: 10.31403/rpgo.v64i2134

3. López E, Becerra-Solano L. Secuencia de bandas amnióticas, una actualización. Arch Argent Pediatr. 2018;116(3):409-420. DOI: 10.5546/aap.2018.e409

4. Castejón Cruz ÓA, Castillo Pérez EA, Varela Carrasco GF, Oviedo Ayala EA, Martínez Hernández PA. Síndrome de Bandas Amnióticas asociado a Secuencia de Potter en el Hospital Regional del Sur, Choluteca, Honduras. Revista Científica. 2016; 14(1): 28-31. Disponible en: http://www.revistasbolivianas.ciencia.bo/scielo.php?scr $\mathrm{ipt}=$ sci_arttext\&pid $=$ S1813-00542016000100011\&lng=es

5. Cignini P, Giorlandino C, Padula F, Dugo N, Cafá EV, et al. Epidemiology and risk factors of amniotic band syndrome, or ADAM sequence. Journal of prenatal medicine. 2012; 6(4):59-63. PMID: 23272276; PMCID: PMC3530965 